CDD: 142.3

\title{
APERCEPÇÃO SUBJETIVA E CONHECIMENTO OBJETIVO: UMA LEITURA SOBRE O LUGAR DO \$18 NA ESTRATÉGIA DA DEDUÇÃO B DA CRÍTICA DA RAZÃO PURA*
}

\author{
PEDRO COSTA REGO \\ pedrorego@onda.com.br
}

Received: 21.07.2010; Accepted: 28.12.2010

\begin{abstract}
Resumo: Neste artigo, procuro avaliar o sentido para o projeto dedutivo da Crítica da Razão Pura da distinção, apresentada no $\$ 18$ dessa obra, entre unidade objetiva e unidade subjetiva da apercepção. Primeiramente, apresento o objetivo geral e os passos fundamentais da dedução transcendental das categorias do entendimento. Em seguida, identifico o esboço de uma estratégia argumentativa, inaugurada no $\$ 18$ da Dedução, fundada na compreensão da unidade subjetiva da apercepção como um juízo de percepção acerca de "objetos subjetivos". Finalmente, defendo que uma dedução assim construída não é uma prova consistente da possibilidade do conhecimento objetivo, na medida em que pretende se furtar à tarefa de demonstrar que as categorias do entendimento são condições da possibilidade da nossa percepção pré-judicativa de objetos sensivelmente intuídos.
\end{abstract}

Palavras chave: Conhecimento. Apercepção. Dedução. Sentido interno.

\section{SUBJECTIVE APPERCEPTION AND OBJECTIVE KNOWLEDGE: A STUDY ON DE ROLE OF \$18 IN THE STRATEGY OF CPR'S B DEDUCTION.}

\begin{abstract}
In this paper I shall investigate the meaning of the distinction, proposed by Kant in section 18 of his first Critique, between objective and subjective unity of apperception for the entire deductive program of this work. Firstly, I shall present my interpretation of the main steps and goals of the transcendental deduction of the categories of understanding. Secondly, I discuss the existence in section 18 of an argumentative strategy grounded upon the interpretation of the subjective unity of apperception as a judgment of perception about "subjective objects". Finally, I argue that a so construed deduction does not amount to a consistent demonstration of the
\end{abstract}

\footnotetext{
* Este artigo foi produzido com o apoio do CNPq, através de bolsa de produtividade em pesquisa.

Manuscrito-Rev. Int. Fil., Campinas, v. 34, n. 2, pp. 523-555, jul.-dez. 2011.
} 
possibility of objective cognition, so far it deflects from the task of demonstrating that the categories are conditions of the possibility of our pre-judicative perception of sensibly intuited objects.

Keywords: Cognition. Apperception. Deduction. Inner sense.

O que propomos nas linhas que seguem é uma reflexão acerca de um momento consensualmente reputado como decisivo da Dedução Transcendental da edição B da Crítica da Raz̃ão Pura (CRP) ${ }^{2}$. Trata-se da entrada em cena, no $\$ 18$, da distinção entre unidade objetiva e unidade subjetiva da apercepção. Admitiremos aqui, como é praxe na literatura secundária envolvida com o tema, que o $\$ 18$ da Crítica pode em alguma medida ser interpretado com o auxílio da controversa distinção apresentada nos \s 18 a 20 dos Prolegômenos entre juízos de experiência e juízos de percepção. Com base nisso, sustentaremos os seguintes pontos que nos parecem essenciais na interpretação da Dedução.

Primeiro: a unidade subjetiva da apercepção do $\$ 18$, entendida como unidade das determinações do sentido interno, possui um papel na estratégia argumentativa da dedução das categorias comprometida com a demonstração da possibilidade do conhecimento objetivo. Isso implica que ela não deve ser considerada meramente como um tipo de unidade representacional com o qual não se deve confundir a unidade categorial da experiência, expressa pelo princípio da apercepção objetiva.

${ }^{2}$ Como referência para as citações da Crítica da Razão Pura, utilizarei a edição da Felix Meiner: Kritik der Reinen Venunft, Hamburg, 1990, assumirei a responsabilidade pelas traduções e, como é praxe, indicarei apenas a paginação das edições originais de 1781 e 1787, A e B respectivamente. Para as demais obras publicadas de Kant, utilizarei preferencialmente a edição da WBD: KANT, I. Werke in zehn Bänden. Hrsg. Wilhelm Weischedel. Darmstadt, Wissenschaftliche Buchgesellschaft, 1983, indicando adicionalmente a numeração das edições originais, onde houver, e para a Briefwechsel e o Handschriftlicher Nachlass, a Edição da Academia (AA): KANT, I. Gesammelte Schriften. Herausgegeben von der Königlichen Preussischen Akademie der Wissenschaften, Berlin und Leipzig, de Gruyter, 1942.

Manuscrito - Rev. Int. Fil., Campinas, v. 34, n. 2, pp. 523-555, jul.-dez. 2011. 
Segundo: é possível identificar nos \s 18 e 19 da Dedução a tentativa de Kant de utilizar a noção de unidade subjetiva da apercepção no contexto de um argumento ad hominem que visa a provar a possibilidade do conhecimento objetivo servindo-se da definição de juízo como pretensão de verdade. Esse argumento exige fundamentalmente duas coisas: (i)que a chamada unidade subjetiva seja compreendida não como ordenação associativa contingente de dados do sentido interno, mas como a unidade de um reconhecimento judicativo de estados subjetivos, vale dizer, como a unidade de juízos de auto-conhecimento; (ii)que se aceite a definição de juízo do \$19, chamada nos Primeiros Princípios Metafísicos da Ciência da Natureza (PPM) ${ }^{3}$ de "definição precisamente determinada de juízo", segundo a qual o juízo é uma conexão de representações conceituais dotada de validade objetiva.

Finalmente: a prova da possibilidade do conhecimento objetivo baseada nesse argumento (i)é insuficiente na medida em que demonstra apenas a necessidade de uma suposição, e não a possibilidade real do conhecimento objetivo; e (ii)não expressa a estratégia refletida e final da Dedução para a prova almejada.

Para tornar essas questões visíveis, percorreremos propedêutica e sumariamente o objetivo geral e os primeiros passos da Dedução Transcendental.

$* * *$

Numa importante passagem da Crítica da Razão Prática (CRPr), Kant indica de modo resumido e preciso o que entende por uma dedução transcendental, justamente quando se trata de sustentar que ela não é o caminho adequado de fundamentação do princípio supremo da moralidade (que é o tema central dessa obra). Diz ele, em primeiro lugar, que deduzir em sentido transcendental é provar que um

${ }^{3}$ Kant, PPM, 8, p.21, AXIX.

Manuscrito-Rev. Int. Fil., Campinas, v. 34, n. 2, pp. 523-555, jul.-dez. 2011. 
determinado princípio ou conceito a priori, vale dizer, independente da experiência, é objetivamente válido; em segundo, que isso deve ser feito através da demonstração de que esse princípio ou conceito é condição da possibilidade do conhecimento de algo; finalmente, que esse algo cujo conhecimento deve ser demonstrado como condicionado pelo princípio a ser deduzido precisa ser algo dado alhures (anderwärts), isto é, dado numa instância em princípio independente daquela a que pertence o conceito a ser deduzido ${ }^{4}$.

Aplicado ao problema do conhecimento teórico, o modelo aponta para uma prova da validade objetiva da unidade da apercepção e das categorias do entendimento dela derivadas. A Dedução deverá provar que as categorias são condições da possibilidade do conhecimento de objetos, entendidos como aquilo cuja representação imediata e singular, vale dizer, cuja intuição empírica, se dá numa instância outra e heterogênea em relação àquela a que pertencem essas categorias, isto é, se dá alhures. Como bem se sabe, essa instância intuitiva outra é, particularmente em sujeitos racionais finitos como nós, apenas a faculdade da sensibilidade espácio-temporal.

Primeiramente, considerando essa prova apenas do ponto de vista do seu objetivo, e não da sua consistência argumentativa, parece claro que a Dedução se acha inteiramente do lado da tese de que é possível um conhecimento ao mesmo tempo universalmente válido vale dizer, fundado em regras necessárias - e objetivo em sentido forte isto é, fundado em regras de síntese de intuições, e não em regras de meras análises de conceitos.

Em segundo lugar, o comprometimento da Dedução com a tese do conhecimento objetivo necessário não parece ser meramente explicativo. Dada a interlocução de Kant com o conjunto da filosofia moderna, é razoável supor que a Dedução se propõe a refutar não

\footnotetext{
${ }^{4}$ Kant, CRPr, 6, p.160, A80. Cf. análise dessa definição em Almeida (1999, p. 62).
} 
apenas o empirismo gnosiológico, mas também o ceticismo em matéria de conhecimento ${ }^{5}$.

A prova da Dedução deve consistir portanto (i)numa demonstração de que as categorias, enquanto conceitos a priori, são condições da possibilidade do conhecimento de dados intuídos; (ii)numa demonstração dessa validade objetiva voltada para um interlocutor que admite ainda menos que um acesso cognitivo $a$ posteriori a objetos, vale dizer, para alguém que admite, no máximo, ter intuições.

Como se sabe, o problema de uma tal prova, admitido e diretamente enfrentado pelo próprio Kant, reside no fato de que a unidade categorial da apercepção não é uma condição da possibilidade da ocorrência em nós de representações singulares e imediatas, vale dizer, de intuições. Com efeito, podemos intuir sem pensar o intuído, assim como podemos pensar outra coisa que não o que intuímos. A radical

5 A esse respeito, cf. a hipótese interpretativa de que o projeto dedutivo da filosofia crítica de Kant assume como interlocutor privilegiado o pensador cético, defendida explicitamente por Edwinn McCann (1985, pp.71-89.), bem como uma antítese a ela formulada por Karl Ameriks (1978), segundo a qual o argumento da dedução da CRP é dirigido antes contra o filósofo empirista. Com base em referências evidentemente kantianas, podemos resumidamente apresentar a distinção essencial, em matéria de conhecimento teórico, entre a posição empirista e a posição cética nos seguintes termos: empirista seria aquele filósofo que, ao menos em princípio, não põe em dúvida a possibilidade do "conhecimento objetivo" - o acesso, no modo de uma subsunção conceitual, a objetos ou estados de coisas considerados como independentes de nossas percepções deles -, e sim a possibilidade de um conhecimento necessário de objetos. Já o cético parece ser antes caracterizado como o pensador que, desconfiando mais do que da possibilidade de um conhecimento a priori, põe em dúvida a possibilidade mesma do conhecimento de objetos (seja ele a priori ou a posteriori), entendido como acesso, no modo da subsunção de intuições a conceitos, a objetos ou estados de coisas independentes e distintos da ocorrência dos nossos estados perceptivos. 
heterogeneidade entre os poderes cognitivos é, em última instancia, o trunfo de um suposto adversário da Dedução, para quem nossas intuições sensíveis podem não ser pensáveis pelos nossos conceitos.

Isso posto, perguntamos: qual é o lugar do $\$ 18$ no percurso estratégico dessa prova e qual é o ganho que a distinção entre as noções de unidade objetiva e unidade subjetiva da apercepção pretende ali assegurar?

$* * *$

O passo avançado no $\$ 18$ é instanciado por um percurso prévio em que duas conquistas argumentativas essenciais são realizadas. Remetemo-nos aqui a elas de modo preparatório e sucinto. $\mathrm{Na}$ primeira, Kant pretende ter garantido que, dado o conceito de um múltiplo de representações consideradas como minhas, pode-se inferir a possibilidade (não a atualidade) do ato consciente de representação de um Eu, vale dizer, a possibilidade de uma apercepção, ou autoconsciência. A explicação é que se tenho consciência, ainda que de modo pré-proposicional, de diversas representações (o que é a condição para que elas possuam o estatuto de representações minhas), tenho que poder me tornar atualmente consciente delas enquanto representações minhas; por conseguinte, tenho que poder me tornar consciente da unidade e identidade de um Eu como instância una e idêntica em que ou para a qual essas representações são representações. $O \mathrm{Eu}$ aqui, convém notar, não passa da única forma possível da unidade do ato de síntese ou combinação pressuposto pelo conceito mesmo de um múltiplo de representações minhas. Esse ponto constitui o essencial do que se convencionou chamar, na esteira da interpretação de Dieter Henrich $^{6}$, de o primeiro passo da Dedução Transcendental, entendida como argumento único em dois passos.

\footnotetext{
${ }^{6}$ Cf. Heinrich (1973, pp. 90-104).

Manuscrito - Rev. Int. Fil., Campinas, v. 34, n. 2, pp. 523-555, jul.-dez. 2011.
} 
A segunda asserção fundamental que antecede o problema aqui proposto é a de que a unidade da apercepção (essa que deve poder acompanhar atualmente, e que acompanha potencialmente todas as minhas representações) é uma unidade objetiva. Aqui começam, queremos crer, as dificuldades que dão origem à comparação entre os dois tipos de unidade aperceptiva de que o $\$ 18$ faz seu tema principal: a objetiva e a subjetivo-empírica, bem como ao desenvolvimento da questão fundamental da segunda parte da Dedução. Com efeito, o argumento kantiano da objetividade nesse momento soa um tanto desconcertante.

Se, por um lado, "objeto" estiver sendo aqui tomado como um algo em geral na medida em que pode ser representado pelo pensamento $^{7}$, temos uma conclusão trivial em relação ao $\int$ anterior, e que, ademais, nada acrescenta para a prova transcendental que a Dedução promete. Simplesmente, a unidade da apercepção é objetiva

7 ...o que Henry Allison chama de uma "acepção lógico-judicativa de objeto", e Strawson, de uma "concepção genérica de objeto". Sobre esse ponto, Allison adota a tese de Henrich do "argumento único em dois passos", concorda com este quanto ao fato de que, em cada passo, Kant opera com uma noção específica de objeto, mas discorda em relação à caracterização de cada uma dessas noções. Para ele, o primeiro passo da Dedução pretende provar a ligação entre as categorias e os objetos entendidos em acepção lógicojudicativa. "Object in sensu logico" parece ser a interpretação do comentador para a noção kantiana de objeto de uma intuição sensível em geral; "an extremely broad sense of object, which encompasses anything that can serve as the subject in a judgment", que ele identifica no emprego por Kant do termo Objekt. Isso equivaleria a dizer que se trata na primeira parte da Dedução de provar a validade objetiva das categorias. Já a segunda pretenderia provar o que ele chama de realidade objetiva das categorias (noção que segundo o comentador "has an ontological sense"), vale dizer, sua referência ao objeto "in a real sense", no sentido de um "actual state of affairs", "an object of possible experience", ou ainda, ao objeto como Gegenstand. Essa tese sofre retificações na segunda versão do livro do comentador, mas as mudanças não atingem, pretende ele, seu conteúdo essencial. Cf. Allison (1983, pp. 135-136). As passagens da Dedução que parecem ter inspirado essa opção interpretativa se encontram em B151/152.

Manuscrito - Rev. Int. Fil., Campinas, v. 34, n. 2, pp. 523-555, jul.-dez. 2011. 
porque, enquanto consciência da unidade de diversas representações minhas, ela é condição necessária e suficiente para que algo em geral seja representado pelo meu pensamento ${ }^{8}$.

Por outro, Kant pode estar tomando aqui “objeto" na acepção crítica plena no termo (o que é mais plausível), a saber, como o resultado do reconhecimento conceitual, segundo regras necessárias, daquilo de que nossas intuições espácio-temporais são representações singulares e imediatas. Nesse caso, a afirmação de que a unidade da apercepção é objetiva só não é gratuita se ela contiver a tese fraca de que a apercepção é uma condição necessária do conhecimento objetivo. Mas entendida no sentido forte de que toda unificação aperceptiva de um múltiplo de representações em geral possui a nota da objetividade epistemológica, a afirmação carece de fundamento ${ }^{9}$. Com efeito, a existência de toda a

${ }^{8}$ Entendendo-se aqui "objeto" como um algo em geral representado, não há qualquer non sequitur, como diagnosticaram alguns comentadores (e como haveria, sem argumento ulterior, se em questão estivesse "objeto" em sentido pleno), entre a tese (i)de que onde há representação de objetos, está suposta a unidade da apercepção e a tese (ii)de que onde há unidade da apercepção configura-se um objeto representado. Isso só parece confirmar a tese do $\$ 15$ de que o sujeito da apercepção não é uma entidade que antecede e efetua a síntese de representações dando ocasião a um objeto. Ele é a (esgota-se na) unidade idêntica e espontânea da ligação de um múltiplo. A esse respeito, cf. Kant, CRP, B133: “...esta identidade completa da apercepção de um múltiplo dado na intuição [sensível em geral] contém uma síntese de representações, e só é possivel pela [grifos meus] consciência dessa síntese", e Paton: "As always in Kant, the unity of apperception and the unity of the manifold mutually condition one another, if indeed they are not to be regarded as identical with one another" $(1965, \mathrm{p} .512)$.

9 Com efeito, embora se possa passar analiticamente do conceito de um múltiplo de intuições espácio-temporais para o pressuposto da unidade da apercepção, não se pode passar analiticamente do conceito de uma apercepção em geral para sua validade objetiva, isto é, para a conclusão de que a unidade da consciência atua ou pode atuar em dados espácio-temporais. O diagnóstico fornecido por Allison para a falácia que nesse ponto se insinua soa mais claro que a sua explicação da interdição. "Por que, pergunta o comentador, se é válido o argumento da primeira parte [da Dedução], a segunda parte é 
segunda parte da Dedução é um testemunho de que o próprio Kant não considera suficientemente explicado até agora (\$16) que a unidade da apercepção seja uma unidade objetiva ${ }^{10}$, ou mesmo que ela possa ser

necessária? Se os data de toda intuição sensível [o que o comentador parece considerar como "objetos" tomados numa acepção meramente lógica] estão necessariamente sujeitos às categorias, a fortiori também estão os dados da intuição sensível humana. Parece então que a única tarefa da segunda parte do argumento seria uma trivial e linear inferência de gênero (intuição em geral) a espécie (intuição humana)” (Allison (1983, p. 134)). Resposta: “...não podemos proceder analiticamente da unidade da apercepção para a unidade do tempo (ou espaço). Não há contradição lógica no pensamento de um número de tempos (ou espaços) que não são partes de um único tempo (ou espaço). Consequentemente, não há nenhum obstáculo meramente conceitual para a possibilidade de unificar sob um conceito num juízo as representações de objetos situados em diferentes horizontes temporais. A moral a ser tirada daqui é que, em virtude de suas formas a priori, a introdução da sensibilidade humana no argumento da Dedução traz consigo um elemento que não pode ser resolvido em termos de requisitos puramente conceituais da unidade da apercepção. É precisamente por isso que o argumento não pode proceder analiticamente do gênero (múltiplo da sensibilidade em geral) para a espécie (múltiplo da sensibilidade humana). É também por isso que as conclusões da Dedução são sintéticas e a priori, apesar da natureza analítica do princípio da apercepção em si" (op.cit., p. 162).

10 Nota-se que num certo momento do $₫ 17$ Kant parece considerar essa

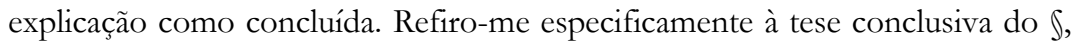
segundo a qual "a unidade sintética da consciência é, portanto [grifo meu], uma condição objetiva de todo o conhecimento, de que preciso não apenas para mim, a fim de conhecer um objeto, mas sob a qual toda intuição tem que estar a fim de se tornar objeto para mim, pois de outra maneira, e sem essa síntese, o múltiplo não se reuniria numa consciência". Tudo indica que a conjunção acima grifada, com ares de conclusão, pretende introduzir algum esclarecimento para a afirmação anteriormente avançada de que "a unidade da consciência é aquilo que unicamente (allein) [grifo meu] perfaz a referência das representações a um objeto, por conseguinte, a sua validade objetiva, e portanto, que se tornem conhecimentos..." (B138). No que segue, procuro mostrar que, considerada à luz da concepção de "objeto" necessária para um argumento transcendental, a segunda afirmação não se sustenta, e que a

Manuscrito - Rev. Int. Fil., Campinas, v. 34, n. 2, pp. 523-555, jul.-dez. 2011. 
uma unidade objetiva. O que parece justificar a necessidade desse prosseguimento é justamente o fato admitido por Kant de que há pelo menos dois tipos de unidade aperceptiva - que passaremos a discutir que não podem ser ditas objetivas. Mais que isso, a existência delas sustenta a suspeita de que nenhuma unidade aperceptiva seja objetiva, tornando a tese do $\$ 17$ antes uma promessa do que uma conclusão.

De um lado, posso reunir na unidade de uma consciência necessária representações que nada têm a ver com minha sensibilidade espácio-temporal. Nesses casos, a unidade aperceptiva que se faz presente é aquela que garante a mera forma lógica de um enunciado em geral, independentemente de sua referência epistêmica. Para esse ponto chama mais claramente a atenção a primeira versão da Dedução, ao indicar a exigência adicional que se impõe a uma unidade aperceptiva que se queira objetiva em sentido estrito: além da unidade da apercepção, objetividade em sentido forte supõe a presença de um algo que, nos termos econômicos de Kant, dawider ist, de algo que se acha diante ${ }^{11}$. Resta portanto a tarefa provar que ainda que nem toda

primeira, embora verdadeira relativamente a qualquer concepção kantiana de "objeto" (à exceção, é claro, de "objeto" como "coisa-em-si"), não justifica a segunda na medida em que apresenta uma condição apenas necessária (portanto insuficiente) da possibilidade do conbecimento objetivo.

11 ...um "diante" que, para nós, somente se oferece como intuição sensível espácio-temporal. Convém mencionar aqui o comentário de Mario Caimi e sua tese interpretativa, se bem a compreendo, da independência lógico-conceitual entre a objetividade das categorias e sua referência a objetos em sentido plenamente crítico. Nos termos do autor, seria possível fornecer uma prova da "objetividade da síntese das representações" (da qual objetividade as categorias seriam condições) fazendo abstração da referência das categorias à "presença efetiva de objetos na sensibilidade", isto é, ao "objeto dado (o que significa, para o sujeito humano, o objeto efetivamente existente na realidade empírica espácio-temporal)". Acredito que o comentador esteja trivialmente correto se entende aqui "efetividade" como "atualidade". Mas sua interpretação parece, além disso, conter a idéia de que uma prova da objetividade das categorias pode prescindir de uma explicitação de sua referência a objetos efetivamente

Manuscrito - Rev. Int. Fil., Campinas, v. 34, n. 2, pp. 523-555, jul.-dez. 2011. 
apercepção seja a reunião de representações intuitivas do que dawider ist, é possível reunir sob regras necessárias de uma auto-consciência o dado espácio-temporal como objeto.

O outro tipo de unidade aperceptiva que não pode, com rigor, merecer o título de objetiva é aquela a que se refere Kant no $₫ 18$ da Dedução com os títulos de "unidade subjetiva da apercepção", ou unidade do "sentido interno". Ao contrário da apercepção lógica, privada de conteúdo intuitivo (nossa intuição), a apercepção subjetiva reúne intuições espácio-temporais. Mas ao contrário daquela que merece o título de "objetiva", a unificação aqui operada é conduzida por regras empíricas (leia-se: contingentes) que têm validade meramente privada, chamadas por Kant noutra parte de "leis de associação" (Gesetzen der Assoziation, Assoziationsgesetze) ${ }^{12}$.

Assim, após o anúncio da problemática tese da objetividade da apercepção no $\$ 17$, o que vemos é todo um percurso que aponta na direção justificar não que toda, mas que alguma apercepção é objetiva.

"dáveis" ou "realizáveis" na intuição bumana. Há algum fundamento textual para essa leitura, por exemplo, em B154: "enquanto fonte de toda ligação, a apercepção e sua unidade sintética dirigem-se ao múltiplo das intuições em geral e, sob o nome de categorias, a objetos em geral antes de toda intuição sensível" (nosso grifo). Por outro lado, "se ao conceito não pudesse ser dada uma intuição correspondente, seria um pensamento segundo a forma, mas sem nenbum objeto..."(B146, nosso grifo). Balanço feito, acredito que haja mais substância textual a favor da tese de que a noção kantiana de objetividade não é identificável, sem mais, às de necessidade e universalidade, e que ela se define não apenas em oposição à contingência, mas também à vacuidade. Nesse sentido, uma dedução plena da objetividade das categorias não se esgota numa prova de sua necessidade analítica relativamente ao conceito de um múltiplo de representações intuitivas minhas em geral. Cf. Caimi (2007, p. 64). Sobre o «dawiden», cf. Kant, CRP, A104.

${ }^{12}$ Cf. CRP, B142, bem como a definição da Didática Antropológica: "A lei da associação <Assoziation $>$ (reunião $<$ Beigesellung $>$ ) é: representações empíricas que freqüentemente se sucedem uma após a outra criam, no ânimo, o hábito de fazer surgir uma sempre que a outra for produzida" (APP, p. 477, BA82).

Manuscrito - Rev. Int. Fil., Campinas, v. 34, n. 2, pp. 523-555, jul.-dez. 2011. 
Atinja Kant ou não esse propósito, ele equivale ao de provar que as categorias, em última instância presentes em todo tipo de apercepção, se aplicam aos dados de nossa intuição e garantem a possibilidade do conhecimento objetivo ${ }^{13}$.

Acreditamos que, do ponto de vista estratégico, tratar-se-á a partir do $\$ 18$ de explorar os pressupostos presentes num dos dois tipos de apercepção distintos da objetiva. Em poucas palavras, a discussão sobre a unidade subjetiva da apercepscão prepara o caminho para a demonstração de que admitir o sentido interno, entendido como a consciência de um diverso de representações temporais unificadas de modo empírico e contingente por meras regras de associação, implica admitir a possibilidade de se conhecer objetivamente aquilo que essa consciência empírica unifica subjetivamente.

Com efeito, o $\$ 18$ começa confirmando a tese da independência conceitual entre apercepção e objetividade: a unidade da apercepção não precisa ser sempre objetiva. Não fica, todavia, imediatamente claro por que a "outra" unidade aperceptiva admitida nesse momento é chamada de subjetiva e, em seguida, de empírica.

${ }^{13}$ Em última instância, esse é o desafio que o próprio Kant impõe ao projeto de uma dedução transcendental das categorias, tal como é anunciado no $\$ 13$ da edição B, a saber, o de refutar a tese da possibilidade de "haver fenômenos constituídos de tal modo que o entendimento não os achasse conformes às condições de sua unidade, e que tudo se encontrasse em tal confusão que, por exemplo, na seqüência da série dos fenômenos nada se oferecesse capaz de fornecer uma regra de síntese e, portanto, correspondesse ao conceito de causa e efeito, sendo esse conceito com isso inteiramente nulo e sem significação" (B123). Observe-se que uma confirmação de que o objetivo da Dedução Transcendental não é apenas o de provar a aplicação (indiscriminada) das categorias aos dados de nossa intuição, mas também provar a possibilidade do conhecimento objetivo (ao contrário do que parece sustentar Allison (1983, p. 172), parece estar disponível algumas linhas acima da passagem citada. Para o Kant do \$13, trata-se de provar "como condições subjetivas do pensamento devam possuir validade objetiva, isto é, fornecer condições da possibilidade de todo conhecimento dos objetos..." (B122). 
Afinal, esses dois títulos não se adaptam bem à designação da apercepção analiticamente derivada no \$16, a qual também é outra que não a objetiva, e é, a rigor, a única com a qual a Dedução esteve às voltas até agora. Esta última, inferida por mera análise do conceito de um múltiplo de representações minhas em geral, é antes uma apercepção lógica - ou analítica - do que empírica. Concederíamos talvez: logicamente subjetiva, mas jamais empiricamente subjetiva. A hipótese mais plausível parece ser a de que, ao contrário da apercepção do \$16, a apercepção subjetivo-empírica é estrategicamente recomendável como ponto de partida da explicação da possibilidade do conhecimento objetivo.

Tudo parece indicar que a introdução do tema da apercepção empírico-subjetiva como contraponto da apercepção objetiva visa a estabelecer a premissa capaz de conectar o argumento da primeira parte como o objetivo final da Dedução. Essa premissa é a consciência de um múltiplo constituido de estados subjetivos temporalmente determinados. Kant parece apresentar aqui o ponto de partida aceito por aquele que ele considera o interlocutor da Dedução, a saber, alguém que espera uma resposta para a seguinte pergunta: como acontece de nossas intuições espácio-temporais se comportarem do mesmo modo que o múltiplo de representações em geral, premissa da prova presente na primeira parte da Dedução? Noutros termos: como ocorre de também nossas intuições se acharem submetidas ao princípio da apercepção originária? O \$18 apresenta o ponto de partida e aponta na direção da estratégia dessa explicação.

Com efeito, vimos que, em sua primeira parte, a Dedução pretende ter provado a validade "objetiva" das categorias relativamente a um múltiplo de representações intuitivas em geral. Em sua segunda e conclusiva parte, o que se afirma é que essa prova deve se dar relativamente aos dados da nossa intuição sensível. Isso equivale a mostrar que o que vale para um múltiplo de representações intuitivas em geral vale para as nossas intuições espácio-temporais. Isto é, também estas se acham subordinadas à apercepção categorial. Trata-se 
afinal de fechar a construção do seguinte raciocínio: (i)todas as minhas representações em geral se acham sob o princípio da apercepção originária (primeira parte); (ii) eu me represento dados espáciotemporais, a saber, numa unidade de consciência chamada de subjetivoempírica (premissa da segunda parte). Enquanto tais, esses dados constituem um sub-conjunto do conjunto das "minhas representações em geral"; (iii)logo, os dados da minha intuição espácio-temporal também se acham sob o princípio da apercepção originária.

Com efeito, o silogismo é trivial na medida em que o passo (i) é analítico, e que é razoável postular o assentimento de (ii) por qualquer interlocutor do kantismo: a admissão de que tem consciência empírica de representações sucessivamente recebidas. Por isso mesmo, a conexão entre o nosso mundo fenomênico e a unidade necessária da apercepção, tema de que se ocupa a segunda parte da Dedução, assume as feições de uma explicação do como, e não propriamente de uma demonstração de que. O que essa explicação estrategicamente almeja é impugnar a contra-tese, em certo sentido intuitiva, de que, em se tratando de dados espácio-temporais, poder-se-ia falar em unidade aperceptiva, mas no máximo de uma unidade aperceptiva subjetiva, desprovida de necessidade e universalidade. Nos \$24-26, Kant procurará mostrar que essa unidade aperceptiva empírica (contingente) e subjetiva, mais imediatamente admissível quando se trata da consciência que temos de nossas intuições sensíveis, é dependente e derivada do princípio da apercepção necessária e originária. Enfim, a pergunta a que a segunda parte da Dedução se propõe a responder é: como ocorre a atuação da apercepção categorial já naquele nível de consciência perceptiva? Resposta kantiana: a apercepção categorial se faz presente já na apreensão consciente de objetos temporais ${ }^{14}$ por meio da chamada síntese transcendental da faculdade da imaginação.

${ }^{14}$ Nessa direção, Allison e Longuenesse pretendem identificar um uso préproposicional ou pré-reflexivo das categorias - um "papel proto-conceitual das categorias" como "regras de apreensão" de dados intuídos (Allison (2004, p.

Manuscrito - Rev. Int. Fil., Campinas, v. 34, n. 2, pp. 523-555, jul.-dez. 2011. 
No que concerne ao nosso propósito neste artigo, confirma-se o sentido da chamada tese da derivação presente no \$18: toda unidade subjetiva e/ou empírica é "derivada da unidade objetiva sob condições dadas in concreto". Por outras, admitir uma concreta unidade subjetiva implica admitir a objetiva como sua condição.

Explicado o plano geral da Dedução e, por conseguinte, a posição refletida de Kant acerca da conexão entre suas duas partes, gostaríamos de defender aqui que o filósofo esboça nos \s 18 e 19 da Dedução um outro caminho para fundamentar a mesma tese - a saber, a tese de que admitir o sentido interno e sua unificação segundo regras de associação implica admitir a possibilidade do conhecimento objetivo. Nossa hipótese é que o andamento do texto esboça nesse momento uma espécie de alternativa argumentativa à explicação do sentido interno meramente associativo condicionado por uma síntese de algum modo categorial. É ao problema da natureza e da plausibilidade dessa

196); Longuenesse (1998, pp. 116-118)) -, que condicionaria a possibilidade mesma da síntese sensível (sentido interno). Segundo essa linha, seria possível inferir do sentido interno o conhecimento objetivo, entendido como resultado do uso conceitual-objetivo daquelas regras categoriais que já se acham, em estado embrionário ("pré-reflexivo"), na base da síntese sensível da apreensão. Mais especificamente, interpretando o que considera um ponto central da leitura de Longuenesse a respeito da aplicação das categorias, Allison afirma, sublinhando a sua autoria em relação às expressões abaixo por mim grifadas, que elas "operam em dois níveis: pré-reflexivamente, enquanto funções lógicas do juízo guiando as sínteses sensíveis da imaginação, e pós-reflexivammente, enquanto conceitos sob os quais objetos são subsumidos em juízos de experiência objetivamente válidos" (Allison (2001, p. 16)). Já na letra da comentadora, trata-se de identificar em Kant a tese de uma "initial application" das categorias, em que elas se acham apenas "engrained in the mind as logical functions" guiando a síntese sensível, e de uma segunda aplicação, quando elas já assumiram o estatuto de "full-fledged concepts" ("categories as concepts"), e respondem por uma "discursive objectively valid combination" (Longuenesse (1998, p. 244)). Para ambos, entretanto, Kant forneceria uma demonstração dessa tese não na Dedução, mas na seção do Esquematismo na Analítica dos Princípios.

Manuscrito - Rev. Int. Fil., Campinas, v. 34, n. 2, pp. 523-555, jul.-dez. 2011. 
alternativa que nos dedicamos a partir de agora. Em resumo, acreditamos encontrar nos \s 18 e 19 uma tentativa de substituir a explicação da presença das categorias na consciência associativa do sentido interno por uma explicação, menos problemática, dessa mesma presença na consciência proposicional dos objetos do sentido interno. Acreditamos também poder sustentar que essa substituição nem é produtiva do ponto de vista do objetivo da Dedução, nem reflete a estrutura final do argumento kantiano.

$\mathrm{O}$ argumento alternativo a que nos referimos envolve basicamente duas decisões interpretativas: a primeira, que a unidade subjetiva da apercepção seja assimilada não ao sentido interno, mas sim à unidade judicativa do auto-conhecimento; a segunda, que a essa unidade se aplique uma definição da essência do ato judicativo. No que segue, avaliaremos o sentido e a plausibilidade dessas duas exigências e, consequentemente, do argumento alternativo que nelas se funda.

***

De saída, poderíamos dizer que a hipótese da unidade subjetiva da apercepção funcionando como premissa do argumento da Dedução soa pouco plausível. O primeiro motivo aponta para dificuldades na definição mesma dessa noção. Kant identifica nas primeiras linhas do $\$ 18$ a unidade subjetiva com o que chama de "determinação do sentido interno". Ocorre que, em princípio, o sentido interno não envolve nenhum ato do pensamento judicativo. Ele apresenta apenas a ordem pré-categorial ou pré-reflexiva em que representações, a saber, volições, desejos, sentimentos e intuições externas se oferecem, ocorrem e se associam na instância do Gemüt. Isso explica por que a Antropologia Pragmática (APP) o define numa oposição em relação à apercepção, seja ela empírica ou transcendental, a qual é, justamente, um ato reflexivo- 
judicativo ${ }^{15}$. Ora, se o sentido interno não é, rigorosamente falando, aperceptivo, tampouco será subjetivamente aperceptivo, de modo que é estranha sua assimilação à unidade subjetiva da apercepção. Mas ainda que se conceda uma solução terminológica localizada para a dificuldade - Kant desvincularia na Crítica a noção de apercepção da de pensamento judicativo -, resta que o fato de se admitir o sentido interno como uma problemática consciência pré-judicativa ao lado da apercepção objetiva parece em nada contribuir para alguma prova da possibilidade dessa apercepção objetiva.

Há motivos, entretanto (evidentemente não imunes a controvérsia), para defender que com a expressão "unidade subjetiva da apercepção" Kant pensa sobretudo uma forma categorial e judicativa de consciência, isto é, algo outro que não sentido interno, embora também outro que não conhecimento de objetos stricto sensu. Trata-se aqui do final do $\$ 18$, quando o que vinha sendo chamado de unidade subjetiva se torna unidade empirica da apercepção, à qual pertence uma validade subjetiva. Pergunta-se então: que fundamentos se tem para compreender a unidade subjetivo-empírica da apercepção como uma consciência judicativa e qual é o ganho que essa compreensão poderia trazer para a estratégia da Dedução? Seguimos aqui a boa sugestão da literatura secundária de um recurso aos textos da Antropologia e dos Prolegômenos para uma resposta à primeira questão.

Seja então mais uma vez o texto da APP. Aqui, Kant define a apercepção transcendental como uma "pura consciência da atividade que constitui o pensar"16. O "objeto" da apercepção transcendental é a unidade de um Eu entendido como condição lógico-transcendental da experiência, e a apercepção é aqui uma consciência de mim mesmo,

${ }^{15}$ Diz Kant ali: sentido interno é "a consciência daquilo de que se é acometido (was der Mensch erleidet) na medida em que se é afetado (affiriert) pelo jogo de seu próprio pensamento". Enquanto a apercepção é definida como "consciência do que se faz", a qual, completa Kant, "pertence ao poder de pensar (Denkungsvermögen)" (Kant, APP, p. 456, BA58).

${ }^{16}$ Kant, APP, pp.424-425, BA24-26.

Manuscrito - Rev. Int. Fil., Campinas, v. 34, n. 2, pp. 523-555, jul.-dez. 2011. 
completa o $\$ 25$ da CRP, "não como apareço para mim, nem como sou em mim mesmo, mas apenas de que sou". ${ }^{17}$

A noção de apercepção empírica é menos clara e parece apresentar uma equivocidade comprometedora. Não é por outra razão que sempre se buscou entender seu emprego no $\$ 18$ da Crítica a partir do recurso a textos paralelos. Em princípio, seu caráter empírico não deveria descaracterizar nem sua natureza conceitual, em oposição ao sentido interno, nem seu foco na direção de um ato do pensamento. Aperceber, seja de modo transcendental, seja de modo empírico, é reconhecer-se judicativamente como a unidade do ato de pensar. Nesse sentido, Allison sugere que a apercepção empírica deveria ser definida como "a consciência da atividade do pensamento tal como ele funciona de modo determinado e com um conteúdo dado", ao passo que seu contraponto, a apercepção transcendental, seria "a consciência dessa mesma atividade de pensar considerada abstração feita de todo conteúdo"18.

Ocorre entretanto que não é (sempre) assim que Kant define a apercepção empírica, o que Paton e Allison são unânimes em reconhecer. Para o primeiro, "Kant sublinha o fato de que os atos judicativos em que a apercepção empírica se manifesta são o reconhecimento ou memória de representações ou estados mentais passados, o que parece incluir (...) o conhecimento [nosso grifo] dos nossos estados mentais". ${ }^{19}$ Para o segundo, "Kant considera apercepção empírica como equivalente a auto-conhecimento empírico [nosso grifo], isto é, como um modo de consciência pelo qual representamos nós mesmos a nós mesmos como objetos do sentido interno" 20 .

\footnotetext{
17 Kant, CRP, B157.

18 Allison (1983, p. 274).

19 Paton (1965, p. 402). E mais: "empirical apperception (...) ought to be the power of understanding as manifested empirically in the recognition of our states of mind. Such recognition no doubt involves inner sense, but empirical apperception and inner sense ought to be different powers" (op.cit., p. 400).

20 Allison (1983, p. 156).
}

Manuscrito - Rev. Int. Fil., Campinas, v. 34, n. 2, pp. 523-555, jul.-dez. 2011. 
É claro que é em flagrante contradição com a tese de que toda apercepção é consciência judicativa de um ato de pensamento que encontramos a mencionada assimilação entre apercepção empírica e auto-conhecimento. Mas é também contraditória em relação àquela tese a identificação entre apercepção empírica e sentido interno. No segundo caso, porque o sentido interno não é uma consciência judicativa ou proposicional. No primeiro, porque o auto-conhecimento não é uma consciência da unidade do ato de pensar, e sim de estados intuitivos internos.

Seja como for, a equivocidade da posição kantiana em relação ao sentido da apercepção empírica no mínimo autoriza a interpretação segundo a qual a unidade subjetiva do $\$ 18$, na condição de unidade empírica da apercepção, significa não o sentido interno, nem a consciência do pensar funcionando com um conteúdo determinado, e evidentemente tampouco uma consciência de si como sujeito lógico do ato de pensar, mas sim um reconhecimento reflexivo-categorial de estados internos entendidos como estados subjetivos. Para designar especificamente esses estados, Gerold Prauss forja a expressão “objetos subjetivos"21. Com efeito, não parece ser sobre outra coisa que Kant se pronuncia no final da Dedução, ao sustentar que "posso ser em geral para mim mesmo objeto, e precisamente objeto da intuição e das percepções internas", e que "no tocante à intuição interna, conhecemos o nosso próprio sujeito (...) como fenômeno...” (B156-7). A possibilidade de um tal auto-conhecimento fenomênico volta a ser tema na seção dos Paralogismos da edição $\mathrm{B}^{22}$, e sobretudo na comumente

21 Cf. a distinção proposta por Gerold Prauss entre "der tranzendental-objektive Gegenstand” e “der tranzendental-subjektive Gegenstand”: (1971, pp. 292-321), bem como a leitura que Allison propõe para ela: Allison (1983, p. 136).

22 Com efeito, Kant aí afirma que "conheço-me (...) se tiver consciência da intuição de mim próprio como de uma intuição determinada em relação à função do pensamento"(B406), e que “o que é objeto não é a consciência de mim próprio determinante, mas apenas determinável, isto é, da minha intuição interna (na medida em que o diverso que ela contém pode adequadamente Manuscrito - Rev. Int. Fil., Campinas, v. 34, n. 2, pp. 523-555, jul.-dez. 2011. 
citada reflexão 565523, que descreve o modo como os estados representacionais subjetivos são introduzidos no tempo objetivo, e portanto no mundo fenomênico, por um ato reflexivo de atenção relativamente ao sentido interno, explicação que parece completar a teoria da atenção da nota ao $\$ 25$ da Dedução.

Considerar a apercepção empírica do $\$ 18$ nesses termos conduz irrecusavelmente a uma reflexão comparativa acerca dos não menos equívocos juízos de percepção dos Prolegômenos. O que se costuma perguntar aqui é se o contrapondo da unidade objetiva da apercepção na Dedução são os juízos de percepção da obra de 83.

Como se sabe, juízos de percepção são caracterizados nos Prolegômenos, em oposição a juízos de experiência, como possuindo validade meramente subjetiva, motivo pelo qual o comentário sempre os aproximou tanto da unidade subjetiva quanto da unidade empírica da apercepção presentes na Dedução Transcendental. Kant, entretanto, parece subscrever a algumas concepções distintas de "validade subjetiva”, o que torna bastante problemática sua definição de juízo de percepção.

No Cânone da CRP (B850), encontra-se a idéia de que um juízo é subjetivamente válido quando ele é simplesmente tomado como verdadeiro pelo sujeito que o enuncia. Validade subjetiva é aqui apenas das Fürwahrhalten de um enunciado. Ora, dado que juízos objetivamente válidos também, e sobretudo eles, podem e tendem a ser tomados por verdadeiros por quem os formula, salta aos olhos que apenas nesses termos não se pode definir juízos de percepção como opostos a juízos de experiência.

A questão parece se resolver a seguir, no conceito de validade privada. Afirma Kant, um juízo de validade subjetiva possuirá validade privada (Privatgültigkeit) se não estiver fundado nas condições de

ligar-se à condição geral da unidade da apercepção no pensamento" (B407). Cf. também B428.

${ }^{23}$ Kant, AA 18: pp. 313-16.

Manuscrito - Rev. Int. Fil., Campinas, v. 34, n. 2, pp. 523-555, jul.-dez. 2011. 
necessidade e universalidade que respondem pela objetividade. As coisas estariam razoavelmente claras se a essa noção de validade privada do Cânone correspondesse nos Prolegômenos a noção de juízo de percepção. Infelizmente ela parece corresponder apenas a uma das acepções do tipo de juízo que, nesta última obra, se opõe ao juízo de experiência.

Ali, de fato juízos de percepção são predominantemente caracterizados como privadamente válidos, especificamente no sentido de que não passam de uma "conexão de percepções no meu estado de espírito"24, ou "uma conexão lógica das percepções num sujeito pensante" 25 . Em princípio, nada mais próximo disso do que o sentido interno, candidato número 1 ao estatuto da controversa unidade subjetiva da apercepção no $\$ 18$ da Dedução.

Ocorre, no entanto, que a idéia de uma conexão lógicojudicativa possuidora de validade meramente subjetiva colide, como se sabe, com a tese do $\$ 19$ da Dedução de que toda conexão lógicojudicativa, vale dizer, todo juízo possui por definição validade objetiva $^{26}$. Isso conduziu muitos intérpretes a ler com mais atenção os exemplos que Kant fornece nos Prolegômenos para juízos de percepção, bem como na Crítica, para juízos de validade subjetiva, e identificar neles não uma mera conexão associativa de percepções, algo como um sentido interno, mas antes o já mencionado reconhecimento judicativo dessas conexões, o que é substancialmente diferente. Trata-se aqui dos juízos do tipo es scheint.

Se lermos os exemplo dos Prolegômenos: "O açúcar é doce", “O quarto é quente" 27 à luz da definição de juízo de percepção, da mesma obra, como "aquele que exprime uma relação da percepção a um

\footnotetext{
${ }^{24}$ Kant, Prolegômenos, 5, §20, p. 166, A82.

${ }^{25}$ Kant, Prolegômenos, 5, §18, p. 163, A78.

${ }^{26}$ Kant, CRP, B141-2.

${ }^{27}$ Kant, Prolegômenos, 5, §19, p. 165, A80-1.

Manuscrito - Rev. Int. Fil., Campinas, v. 34, n. 2, pp. 523-555, jul.-dez. 2011.
} 
sujeito" 28 , tendemos a traduzi-los em juízos do tipo: "sinto o açúcar como doce", "percebo o quarto como quente". Diga-se de passagem, isso só vem a se confirmar no exemplo de validade subjetiva da Dedução: "quando carrego um corpo, sinto uma pressão de peso". Ora, sentir ou perceber que P não é o mesmo que asserir que "sinto que P", ou "percebo que P".

Na primeira versão do seu livro sobre a CRP, Allison pretende explicar essa equivocidade nos seguintes termos: na primeira acepção, subjetivamente válido é um juízo que "holds only for the subject", vale apenas para o sujeito; na segunda, é um juízo supostamente verdadeiro "merely of the subject", acerca, sobre o sujeito, a saber, sobre seus estados perceptivos ${ }^{29}$. O decisivo aqui é que, quando se compreende "subjetivamente válido" nessa última acepção, a saber, como "sobre o sujeito", tem-se a vantagem de driblar a incompatibilidade dos juízos de percepção relativamente à cláusula restritiva do $\$ 19$ da Dedução. É que, num certo sentido, juízos assim subjetivamente válidos são também objetivamente válidos, ou, possuem validade objetiva. A explicação para isso, encontramos mais uma vez em Prauss: juízos "sobre", "acerca" de estados perceptivos do sujeito são, é bem verdade, juízos inverificáveis e por isso mesmo incorrigíveis por outros sujeitos ${ }^{30}$. Mas disso não segue que eles não possam ser objetivamente válidos enquanto atos de reconhecimento categorial e judicativo de estados perceptivos, se pudermos entender, como Kant o faz, estados perceptivos como ocorrências temporais no mundo fenomênico. Nesse mesmo sentido, convém medir com cuidado a aparente tese dos Prolegômenos de que validade objetiva se identifica e, mais, se dilui na noção de validade universal, entendida como inter-subjetividade. Se a validade objetiva de um juízo fosse o mesmo que sua real corrigibilidade por outros sujeitos, seria contraditório atribuir estatuto judicativo a alguma auto-consciência

\footnotetext{
${ }^{28}$ Kant, Prolegômenos, 5, §18, p. 164, A79.

29 Allison (1983, p. 151).

${ }^{30}$ Cf. Prauss (1971, p. 234).
}

Manuscrito - Rev. Int. Fil., Campinas, v. 34, n. 2, pp. 523-555, jul.-dez. 2011. 
empírica, e, por conseguinte, seria contraditório o próprio conceito de auto-conhecimento ${ }^{31}$.

Isso posto, temos que constatar que as duas acepções de juízo de percepção nos Prolegômenos parecem bastante próximas das duas acepções daquela unidade de apercepção que, na letra do \18 da Dedução, se opõe à unidade objetiva. A unidade subjetiva da apercepção enquanto sentido interno possui certamente aquela mesma validade subjetiva, entenda-se: privada, associativa e pré-categorial, dos juízos de percepção na primeira acepção dos Prolegômenos. Por sua vez, a unidade empírica da apercepção parece muito próxima da unidade do ato de pensamento reflexivo pelo qual o sujeito reconhece judicativamente o conteúdo de seu sentido interno, isto é, muito próxima dos juízos de percepção enquanto juízos do tipo es scheint ${ }^{32}$.

A contribuição desse recurso à Antropologia e aos Prolegômenos para nossa reflexão sobre o $\$ 18$ da Crítica pode então ser resumida: trata-se da confirmação da possibilidade de se ler a unidade subjetiva da apercepção da última obra como auto-conhecimento e como juízo de percepção do tipo es scheint: em suma, com uma consciência judicativa. Quanto à segunda questão que propusemos acima - qual é o ganho que essa leitura poderia trazer para a estratégia da Dedução? - trata-se de discutir a natureza e a plausibilidade do argumento alternativo que Kant esboça nos \s 18 e 19 da Dedução.

O ganho consiste essencialmente em que a unidade subjetiva da apercepção como juízo (de percepção) torna, sem dúvida alguma, mais palatável a "tese da derivação" do \$18. Admitida essa leitura alternativa, resulta que não é mais o sentido interno, e sim o auto-

31 Além disso, diria o atual Estagirita, não é porque pensamos todos que tu és branco que tu és branco; antes, pensamos todos assim porque tu és branco...

${ }^{32}$ É claro que o primeiro caso, o do sentido interno e a validade privada que lhe corresponde, dificilmente tolera o título de juízo, dada a já mencionada tese do $\$ 19$ da Dedução, segundo a qual validade objetiva é uma nota característica do conceito mesmo de juízo. Mas não é impossível que esse ponto específico corresponda a uma dificuldade terminológica. 
conhecimento que implica a possibilidade do conhecimento objetivo, na medida em que deriva dele. A vantagem é que a partir de agora, toda passagem argumentativa que se pretende pode acontecer no nível da consciência judicativa, sem que seja necessário enfrentar o delicado problema da heterogeneidade entre um sentido interno pré-judicativo e o juízo de experiência, cuja possibilidade se deseja provar. Com efeito, a tese da derivação passaria assim a exigir "apenas" a explicação de que a admissão de uma consciência judicativa subjetiva (juį̧o de percepção) supõe a admissão da possibilidade de uma consciência judicativa objetiva (conhecimento objetivo), na medida em que aquela é derivada desta.

É claro, entretanto, que a assimilação entre unidade subjetiva e auto-conhecimento não é suficiente para o argumento alternativo inaugurado no \$18. O que Kant precisa para completá-lo é uma teoria que explique a passagem dos juízos de percepção assim entendidos para os juízos de conhecimento objetivo em sentido estrito. Acreditamos que, nesse momento da Dedução (\$19), o filósofo lança mão da teoria da forma lógica do juízo com esse fim.

Kant parece refletir sobre essa estratégia já um ano antes da publicação da Dedução B, a saber, na mencionada nota dos $\mathrm{PPM}^{33}$. Ali, afirma-se que a tarefa da Dedução pode se realizar "quase por uma única inferência a partir de uma definição precisamente determinada de um juízo em geral (uma ação através da qual representações dadas tornam-se primeiramente cognições de um objeto)". Qual seria então a relação entre a "definição precisamente determinada de juízo em geral" e o valor estratégico - que nesse momento Kant parece vislumbrar - da unidade subjetiva da apercepção entendida como juízo acerca de estados subjetivos, e não como sentido interno?

Há pouco dizíamos que é um propósito da Dedução Transcendental, se não o propósito essencial, provar a validade objetiva das categorias demonstrando, e não pressupondo, a possibilidade do conhecimento de estados de coisas objetivos, entendidos como

${ }^{33}$ Cf. nota 3.

Manuscrito - Rev. Int. Fil., Campinas, v. 34, n. 2, pp. 523-555, jul.-dez. 2011. 
distintos dos estados representacionais meramente subjetivos e privadamente válidos. Enquanto o \$16 estabelece o princípio da apercepção originária e o $\$ 17$ o conecta com a noção de objetividade, o §18 admite o caráter problemático dessa conexão quando assume que a dependência do conhecimento objetivo relativamente à unidade da apercepção não torna toda unidade aperceptiva uma unidade objetiva; antes, resta a possibilidade de uma apercepção meramente subjetiva. Ora, a ameaça cética ${ }^{34}$ que a Dedução precisa enfrentar é precisamente

34 Allison atribui a tese de que a Dedução pretende ser uma refutação do ceticismo a uma certa "contemporary analytic reading" inspirada essencialmente por Strawson e que assumiria em Bennett sua versão mais agressiva. $\mathrm{O}$ autor não deixa de se alinhar a essa corrente de leitura ao concluir que a Dedução não produz esse resultado, mas discorda dela ao defender que a Dedução sequer ergue uma tal pretensão. Cf. Allison (1983, pp. 171-2) (a numeração indicada a seguir refere-se a essa obra). Para o comentador, a primeira parte do argumento da Dedução, que é "analítica", não faz mais que "demonstrar a validade objetiva das categorias em relação a objetos entendidos em sentido judicativo, ou lógico" (p.171). A segunda, a rigor, seria "motivada por dois interesses distintos": um deles, satisfatoriamente consumado, consistiria em estabelecer a realidade objetiva das categorias através de uma demonstração de que elas "necessariamente se aplicam aos dados sensíveis da intuição humana"; o outro seria o de "mostrar que [as categorias] de algum modo tornam possível a experiência” (p.136). Este último seria equivalente ao interesse de demonstrar que "temos genuína experiência de objetos em sentido forte, que são distintos de nossas percepções deles" (p.171), ou o interesse de fundamentar a distinção entre, de um lado, "conhecimento empírico de objetos e de uma ordem objetiva"; de outro, "percepções e sua ordem subjetiva" (p.136). É este objetivo, que Kant buscaria na versão B da Dedução "esforçando-se por conectar as categorias com a experiência após ligá-las à síntese da apreensão" (p.171), que o comentador considera inalcançado "mesmo sob a mais caridosa das interpretações (p.136). Convém observar que na segunda versão de seu livro (2004), Allison mitiga o relativo fracasso previamente diagnosticado da Dedução, identificando o "defeito" e as "ambigüidades" aí presentes como incompletude, a ser resolvida nas seções do Esquematismo e da Analítica dos Princípios. Para Paul Guyer, a refutação do ceticismo gnosiológico é positivamente um projeto da Dedução - a saber, fracassado -, e não um

Manuscrito - Rev. Int. Fil., Campinas, v. 34, n. 2, pp. 523-555, jul.-dez. 2011. 
a da possibilidade de uma indistinção entre o mundo subjetivo da mente e o mundo objetivo do conhecimento, o que é o mesmo que a indistinção entre unidade objetiva e unidade subjetiva da apercepção. Assim, é razoável que Kant pretenda aqui fornecer um argumento capaz de mostrar que a admissão, por parte do sujeito, da unidade subjetiva de um mundo mental implique de algum modo a admissão, no mínimo, da possibilidade de um conhecimento de estados objetivos.

Sabe-se que o $\$ 19$ da Dedução é essencialmente o anúncio da controvertida tese da validade objetiva como forma lógica do juízo. Muito se discute tanto sobre o sentido da expressão "forma lógica" no

programa firmado para seções ulteriores. Entretanto, prossegue ele, a prova da validade objetiva das categorias não deixa de ser uma consistente refutação do ceticismo gnosiológico, mas somente quando Kant abandona o método empregado na Dedução - na qual "what Kant bimself explicitly recogniżed as a transcendental deduction always assumes a synthetic but necessary truth for its premise" (Guyer (1987, pp. 77-78)) - e avança, na Analítica dos Princípios, a inferência de regras categorias necessárias diretamente a partir da natureza temporal de um múltiplo em geral. Convém observar todavia que, dadas as dificuldades semânticas concernentes à "unidade subjetiva/empírica" do $\$ 18$, não é inequívoco que, para Guyer, a dedução consistente operada por Kant somente "após" a "Dedução" seja exatamente uma inferência da unidade objetiva da apercepção a partir da unidade subjetiva da apercepção. Um argumento a favor dessa aproximação repousa no fato de que, como veremos a seguir, a referida unidade subjetiva é assimilada pelo filósofo ao sentido interno, cuja forma é justamente o tempo, ponto de partida privilegiado pela análise de Guyer. Por outro lado, se não pudermos compreender a apercepção subjetiva a que se refere o $\$ 18$ estritamente como consciência do múltiplo temporal - e tivermos que tomá-la como auto-consciência - então a posição de Guyer seria a de que esse \, como toda a Dedução, padeceria da mesma inconsistência metodológica que consistiria em assumir como ponto de partida do argumento uma "a priori certainty of the numerical identity of the self in any possible manifold" (que seria explicada unicamente por um ato a priori de síntese, o qual precisa ter as categorias a fundamento), o que tornaria o argumento refém de um "claim to certitude in a priori knowledge, which Kant does not and cannot sustain" (Guyer (1989. p. $57))$.

Manuscrito - Rev. Int. Fil., Campinas, v. 34, n. 2, pp. 523-555, jul.-dez. 2011. 
contexto de uma lógica que não é geral, mas sim transcendental, quanto sobre o que se deve entender aqui por validade objetiva. Essa expressão no texto de Kant foi compreendida por alguns como (i)verdade, por outros como (ii)valor de verdade; como (iii)valor de verdade determinável pelos recursos das faculdades humanas e, finalmente, o que aqui parece o mais pertinente, (IV)como pretensão de verdade, isto é, pretensão de correspondência a objetos entendidos como algo nãoconceitual ${ }^{35}$.

Por razões evidentes, passamos agora por cima do que seria uma longa discussão justificativa desse último sentido. Importa que, se a validade objetiva aqui atribuída à forma lógica do juízo como nota característica é a mesma que cabe à unidade objetiva da apercepção do $\int$ anterior, o 18, então, do ponto de vista de uma estratégia da Dedução, pode parecer desejável que a unidade subjetiva ou empírica da apercepção assuma uma forma judicativa. É que nesse caso, ela traz em si, no mínimo implicitamente, a objetividade cuja possibilidade se deseja provar.

Eis então no que consistiria o que temos chamado aqui de "argumento ad hominem 36 alternativo" e de "atalho argumentativo"

35 Considero aqui a noção de validade objetiva como nota de um conceito de juízo pertencente à Lógica Geral, e não exclusivamente à Transcendental. A interpretação (i) é flagrantemente inconsistente. A (iii) impede que sejam juízos tanto os juízos sintéticos a posteriori com sujeito quantificado universalmente, quanto os chamados juízos metafísicos. A (ii), candidato mais forte, autoriza o primeiro caso, mas não o segundo, diferentemente da (iv), para a qual a pretensão, segundo problemática passagem do $\$ 19$ da Dedução, embutida na cópula independe da eventual impossibilidade de verdade e falsidade no resultado da ligação entre representações conceituais. Sobre a noção de validade objetiva como pretensão de verdade, cf. Guerzoni (1998, pp. 129157).

36 Uso aqui a expressão na acepção segundo a qual se trata de contrapor ao interlocutor conseqüências de teses por ele aceitas (Cf. Abbagnano, N. Dicionário de Filosofia, p. 17; Locke, J. Ensaio acerca do entendimento bumano, IV, p. Manuscrito - Rev. Int. Fil., Campinas, v. 34, n. 2, pp. 523-555, jul.-dez. 2011. 
esboçado nos \s 18 e 19 da Dedução. Primeiro: todo juízo possui, segundo a mencionada "definição precisamente determinada", validade objetiva, isto é, implica uma pretensão de verdade; uma pretensão de caracterização universalmente válida de estados de coisas objetivos. Isso vale mesmo para aqueles juízos que se voltam para "objetos subjetivos", isto é, juízos de percepção. Segundo: a unidade subjetiva da apercepção, enquanto apercepção empírica, é um juízo, e não uma consciência pré-categorial e meramente associativa. Conclusão: o mero exercício de atualização de minha consciência empírica de estados subjetivos prova que suponho a possibilidade do conhecimento objetivo. A explicação é que não posso ao mesmo tempo julgar, isto é, erguer uma pretensão de verdade, sem supor que seja possível isso que pretendo, a saber, conhecer objetivamente.

Em poucas palavras, e aplicando a polissemia sugerida por Allison, temos que o adversário da Dedução aceita, de saída, apenas a existência de conexões representativas subjetivas, no sentido de "válidas somente para o sujeito". Mas ao aceitar caracterizar essas conexões em juizos, ele admite a existência de conexões representativas subjetivas no sentido de "válidas sobre o sujeito". Ora, em virtude da definição mesma de juízo, ligações representativas judicativas válidas sobre o sujeito são juízos sobre objetos, a saber, objetos subjetivos, mas ainda assim objetos. Como tais, esses juízos erguem pretensão de verdade. Ora, pretensão de verdade é precisamente o que o adversário da Dedução considera uma ilusão. Assim, esse adversário acaba afirmando precisamente o que ele pretende negar, a saber, que tem sentido pretender conhecer objetivamente.

203, xxvii, 21), e não na acepção depreciativa de um argumento contingente, singular e pessoal.

Manuscrito - Rev. Int. Fil., Campinas, v. 34, n. 2, pp. 523-555, jul.-dez. 2011. 
Acreditamos que, em conjunto, a adução de uma unidade subjetiva contraposta à apercepção originária, a tese da derivação, a definição de juízo nos \s18 e 19 da Crítica e o conteúdo da nota do Prefácio de 86 sejam indícios suficientes de que Kant considerou seriamente essa estratégia para refutar a tese cética sobre a impossibilidade do conhecimento objetivo. Mas acreditamos também que se tivesse ficado satisfeito com esse esboço de argumento, teria dado por encerrado ali o percurso da Dedução Transcendental, deixando de lado a sua segunda parte, bem como a seção da Refutação do Idealismo que parece ser seu acabamento. Em suma, tendo provado a necessária suposição de que é possível conhecer objetivamente, já não seria preciso se esforçar para provar, no $\$ 26$, que ou como objetos espácio-temporais se conformam ao princípio da apercepção originária.

Para terminar, gostaríamos de apontar a dificuldade essencial, provavelmente constatada por Kant, em relação ao caminho caracterizado acima. Não podemos defender que a admissão dos juízos de percepção, entendidos segundo a leitura de Prauss, associada a uma teoria da validade objetiva como forma lógica do juízo, conduz realmente a uma prova da possibilidade do conhecimento objetivo. Não nos referimos aqui, pelo menos de início, à dificuldade presente no caráter meramente definitório do argumento no que concerne à noção de juízo. Com relação a esse ponto, observamos somente que o interlocutor da Dedução pode não aceitar que, ao expressar pensamentos através da ligação de representações, esteja se servindo do discurso como um meio para apreender a existência objetiva de estados mentais. Em outras palavras, ele não precisa, em princípio, aderir a uma concepção correspondentista de juízo.

Mas deixamos de lado essa dificuldade. Referimo-nos antes ao fato de que no argumento, ainda que se aceite a natureza judicativa da consciência dos nossos estados internos, não é a possibilidade mesma de conhecer objetos o que é demonstrado como uma condição da 
possibilidade de caracterizar conceitualmente esses estados mentais. A possibilidade do conhecimento aparece aqui, antes, como uma suposição psicológica (ou, na melhor das hipóteses, modal) necessária do sujeito que admite julgar sobre suas percepções.

Dito de outro modo, o que o argumento sustenta é que para julgar sobre minhas percepções, não posso deixar de acreditar, em virtude do caráter no mínimo assertórico de todo juízo tomado isoladamente, que é possível conhecer objetos ${ }^{37}$. Mas isso, observa-se, não exclui que seja impossível conhecer objetos, e que minha suposição de que é possível esteja equivocada. Ora, a prova a que parece almejar Kant na Dedução não é a da necessidade de uma crença, mas a da necessidade de uma possibilidade, a qual independe, a princípio, da crença nela e, logicamente, precede a crença nela.

$37 \mathrm{O}$ tema da assertividade merece uma consideração mais detida, que, infelizmente, não pode ser elaborada neste artigo. A título de mero anúncio para desenvolvimento ulterior, o que proponho é uma identificação entre a pretensão de verdade da definição de juízo (que a Dedução, em B141, caracteriza com a expressão darauf zielt como explicação do sentido da cópula) e a noção modal de assertividade. Não ignoro as evidentes dificuldades dessa sugestão: afinal, (i) anexar a modalidade da asserção à intensão do conceito de juízo deveria implicar que juízos não-assertóricos, a saber, problemáticos e apodíticos, são uma contradição em termos (se não são assertóricos, não seriam juízos); além disso, (ii) Kant confere um título especial e distintivo aos juízos assertóricos (categóricos), a saber, proposição, o que parece indicar que a nota da assertividade pertence a um tipo de juízo, em vez de designar a "essência" do juízo; e finalmente, (iii) encontramos na Lógica a tese de que "julgo sobre muita coisa que não decido" (Kant, Lógica Jäsche, AA 09: 109, A170) o que sugere que "decidir" é comportar-se assertoricamente em relação a uma conexão de representações, enquanto julgar seria a operação "anterior" que consiste apenas em ligar representações conceituais, abstração feita da decisão modal. Para sustentar minha leitura, acredito ser possível defender (noutra ocasião), em primeiro lugar, que há um sentido em que são compatíveis a assertividade e as demais modalidades num mesmo juízo, e em segundo lugar, que juízos categóricos, hipotéticos e disjuntivos são, num certo sentido, sempre assertóricos.

Manuscrito - Rev. Int. Fil., Campinas, v. 34, n. 2, pp. 523-555, jul.-dez. 2011. 
Dizer que a auto-consciência empírica supõe a possibilidade do conhecimento objetivo não deve ser idêntico a dizer que o sujeito dessa auto-consciência tem que acreditar na possibilidade do conhecimento objetivo. A rigor, ele tem que (racionalmente) acreditar nessa possibilidade pelo fato de que essa possibilidade existe, e não pelo fato de que ele (i)julga, (ii)aceita a definição de juízo como pretensão de conhecimento objetivo e (iii)admite que a crença na possibilidade desse conhecimento objetivo é uma condição de erguer racionalmente uma tal pretensão. Nesse sentido, a definição de juízo figuraria problematicamente na forma do mencionado argumento ad hominem como uma tentativa de substituir, e não de implementar, a prova da possibilidade do conhecimento objetivo.

À guisa de conclusão: seria exagerado condenar como equivocada a estratégia esboçada nos \s 18 e 19 da Dedução, fundada na associação entre a unidade subjetiva da apercepção entendida como juízo e a definição de juízo como pretensão de objetividade. Mas deveríamos dizer que essa estratégia não conduz ao que é textualmente um objetivo da dedução: demonstrar que é possível conhecer objetivamente, uma vez que nossos conceitos se aplicam às nossas intuições.

\section{REFERÊNCIAS BIBLIOGRÁFICAS}

ALLISON, H.E. Kant's Theory of Taste. Cambridge, Cambridge University Press, 2001.

. Kant's Transcendental Idealism: an interpretation and defense. New Haven and London: Yale University Press, 1983.

Kant's Transcendental Idealism: an interpretation and defense. (revised \& enlarged edition) New Haven and London: Yale University Press, 2004. 
ALMEIDA, G. "Crítica, Dedução e Facto da Razão". Analytica, v.4, $\mathrm{n}^{\mathrm{o}} .1$, Rio de Janeiro, 1999.

AMERIKS, K. "Kant's Transcendental Deduction as a Regressive Argument". Kant-Studien, n. 69, 1978.

CAIMI, M. La déduction transcendentale dans la deuxième édition de la Critique de la raison pure. Paris: Publications de la Sorbonne, 2007.

HEINRICH, D. "Die Beweisstruktur von Kants tranzendentaler Deduktion”. In: Prauss, G. (ed.) (1973), pp. 90-104.

GUERZONI, J.A. "A essência lógica do juízo: algumas observações acerca do $\$ 19$ da Dedução Transcendental (B)". Analytica, v.3, n. 2, pp. 129-157, Rio de Janeiro, 1998.

FÖRSTER, E. (ed) Kant's Transcendental Deductions: The three 'Critiques' and the 'Opus postumum'. Stanford: Stanford University Press, 1989.

GUYER, P. Kant and the Claims of Knowledge. Cambridge: Cambridge University Press, 1987.

GUYER, P. "Psychology and the transcendental deduction". In: Eckart Förster (Ed.) (1989), pp. 47-68.

KANT, I. Werke in zehn Bänden. Hrsg. Wilhelm Weischedel. Darmstadt, Wissenschaftliche Buchgesellschaft, 1983. - Gesammelte Schriften. Hrsg.: Bd. 1-22 Preussischen Akademie der Wissenschaften, Bd. 23 Deutsche Akademie der Wissenschaften zu Berlin, ab Bd. 24 Akademie der Wissenschaften zu Göttingen. Berlin: 1900ff.

LONGUENESSE, B. Kant and the Capacity to Judge. Princeton and Oxford: Princeton University Press, 1998.

McCANN, E. "Skepticism and Kant's B Deduction". History of Philosophy Quarterly, v. 2, n. 1, pp. 71-79, 1985. 
PATON, H. J. Kant's Metaphysic of Experience. New York: George Allen \& Unwin LTD, The Humanities Press, 1965.

PRAUSS, G. Erscheinung bei Kant. Berlin: de Gruyter, 1971. . (ed) Kant zur Deutung seiner Theorie von Erkennen und Handeln. Köln: Verlag Kiepenheuer \& Witsch, 1973. 